\title{
Perancangan dan Implementasi Sistem Otentikasi OAuth 2.0 dan PKCE Berbasis Extreme Programming (XP)
}

\author{
Rahmat Kurniawan ${ }^{* 1}$ \\ ${ }^{1}$ Universitas Mercubuana Yogyakarta, Indonesia \\ Email: ${ }^{1}$ rahmatkurniawan339@gmail.com
}

\begin{abstract}
Abstrak
Perusahaan XYZ adalah sebuah perusahaan swasta yang menyediakan sebuah produk Hospital Management System (HMS) yang bersifat subscription. Dimana lebih dari satu rumah sakit menggunakan produk ini dengan satu server yang terpusat. Permasalahan yang ingin diuji pada penilitian ini adalah adalah bagaimana merancang sistem otentikasi dan otorisasi untuk sistem HMS multitenant sehingga sistem tidak bisa digunakan oleh pihak yang tidak terdaftar. Tujuan penelitian ini adalah merancang dan menerapkan prosedur otentikasi dengan mekanisme otentikasi OAuth 2.0 dan PKCE pada aplikasi HMS multitentant dengan melibatkan suatu server dan client dalam melakukan proses otentikasi untuk mempermudah proses otentikasi pada tiap tenant. Pada penelitian ini akan melibatkan tiga aplikasi. Satu aplikasi sebagai middleware dimana terdapat halaman sign-in berbasis OAuth 2.0. Dan dua aplikasi lagi sebagai client dan server. Pada penelitian ini dilakukan proses pengembangan sistem menggunakan metode Extreme Programming $(X P)$. Hasil dari penelitian ini berupa sistem login atau sistem otorisasi dan otentikasi yang secara nyata dapat memenuhi kebutuhan perusahaan XYZ. Sistem login ini memiliki kelebihan dimana mempermudah perusahaan XYZ untuk mengatur client yang terintegrasi dengan sistem ini dan bagi client mudah untuk menimplementasikannya.
\end{abstract}

Kata kunci: Authorization Server, OAuth 2.0, Otentikasi dan Otorisasi. PKCE.

\section{Design and Implementation of Authentication System OAuth 2.0 and PKCE Based on Extreme Programming (XP)}

\begin{abstract}
XYZ Company is a private company that provides a subscription Hospital Management System (HMS) product. Where more than one hospital uses this product with one centralized server. The problem to be tested in this research is how to design an authentication and authorization system for a multitenant HMS system so that the system cannot be used by unregistered parties. The purpose of this study is to design and implement authentication procedures with OAuth 2.0 and PKCE authentication mechanisms on multitentant HMS applications by involving a server and client in the authentication process to facilitate the authentication process for each tenant. This research will involve three applications. One application as middleware where there is a sign-in page based on OAuth 2.0. And two more applications as client and server. In this study, the system development process was carried out using the Extreme Programming (XP) method. The result of this research is a login system or authorization and authentication system which can actually meet the needs of XYZ company. This login system has the advantage that it makes it easier for XYZ company to manage clients that are integrated with this system and for clients it is easy to implement it.
\end{abstract}

Keywords: Authentication and Authorization, Authorization Server, OAuth 2.0, PKCE.

\section{PENDAHULUAN}

Seiring dengan perkembangan internet, hampir semua sistem atau informasi dapat diakses melalui internet. Sehingga memungkinkan seseorang untuk mengakses suatu informasi dari mana saja. Namun karena bisa di akses dari manapun dan kapanpun sehingga sebuah aplikasi web rentang terhadap pencurian data terutama untuk data user [1]. Untuk mengatasi masalah ini suatu aplikasi web disarankan untuk menggunakan suatu protokol keamanan saat melakukan proses login. Protokol keamanan itu disebut OAuth 2.0.

OAuth 2.0 merupakan protokol keamanan yang digunakan dalam proses otentikasi user [2]. OAuth 2.0 sendiri sudah digunakan di hampir seluruh dunia, dari penyedia skala besar seperti Facebook dan Google bahkan di sebuah perusahaan startup [3]. OAuth 2.0 memungkinkan aplikasi pihak ketiga untuk mendapatkan akses 
terbatas ke layanan HTTP, baik atas nama resource owner dengan mengatur interaksi persetujuan antara pemilik sumber daya dan layanan HTTP, atau dengan mengizinkan aplikasi pihak ketiga untuk mendapatkan akses atas namanya sendiri [4].

Pada implementasi OAuth 2.0 ada proses authorization code. Dimana diproses ini memberikan token kepada public client [5]. Sayangnya, proses ini bergantung pada aplikasi yang menyediakan client secret dalam permintaan terakhir untuk access token. Untuk jenis aplikasi tertentu, itu membuat celah terhadap kebocoran kerahasian data dan hal ini tidak dapat dihindari. Karena ini adalah klien publik, tidak ada cara untuk menjamin keamanan rahasia yang digunakan untuk pertukaran token. Menggunakan implicit flow bisa menyelesaikan masalah itu tetapi menambah risiko mengekspos token akses di URI, yang dimana membuat proses ini rentan terhadap intersepsi aplikasi berbahaya.

Solusi ini dapat diterima dan diperlukan saat aplikasi tidak dapat membuat permintaan lintas domain sehingga mustahil untuk menyelesaikan proses authorization code. Namun sekarang CORS didukung secara luas, jadi aplikasi bisa membuat request langsung kepada token endpoint.

Dan tanpa adanya masalah cross-origin, klien publik bisa memanfaatkan authorization code dengan menggunakan tambahan $P K C E$, dimana untuk menggantikan client secret dengan string yang dibuat secara dinamis. Dengan begitu, PKCE menghilangkan risiko kebocoran kerahasian data sambil mengizinkan server otorisasi untuk memverifikasi bahwa aplikasi yang meminta token akses sama dengan yang memulai proses OAuth [6].

Untuk itu salah satu solusi untuk menghindari kebocoran data saat proses otentikasi yang diharapkan dapat diterapkan dan dilakukan dengan cara menambahkan PKCE pada OAuth 2.0. Berdasarkan latar belakang yang telah disampaikan, maka dibuatlah suatu penelitian dengan merancang sistem login yang menggunakan metode otentikasi OAuth 2.0 dengan menambahkan PKCE pada proses login sebuah website.

\section{METODE PENELITIAN}

Pada penelitian ini menggunakan metodologi penilitian Extreme Programming karena pada XP lebih menekankan pada praktik rekayasa perangkat lunak daripada manajemen proyek. Dan XP juga lebih fokus pada engineer daripada project manager. Berikut tahapan-tahapan metodologi dalam penelitian ini, seperti pada Gambar 1.

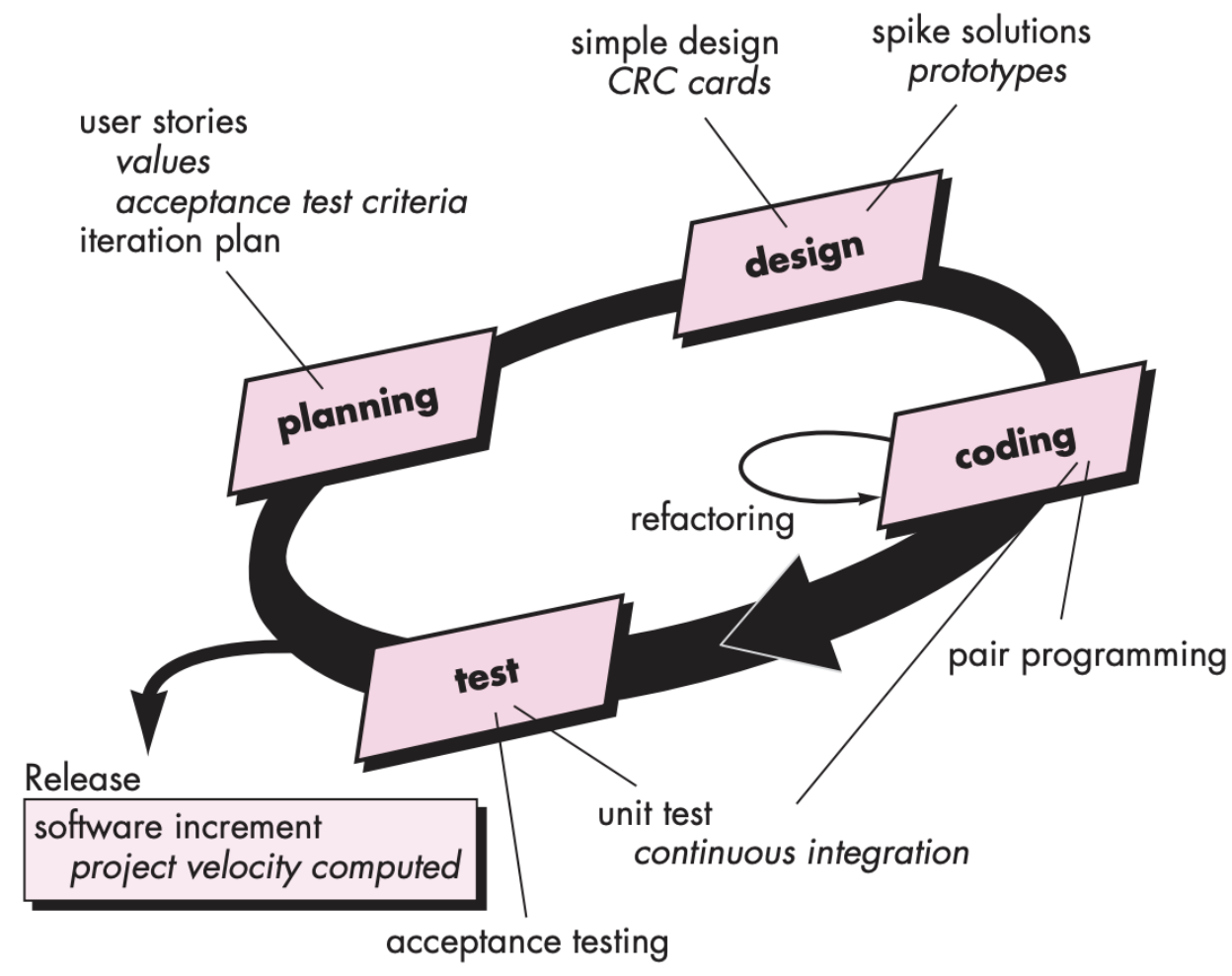

Gambar 1 Proses Extreme Programming (XP) [7] 
Penjelasan tahap-tahap yang tertera pada Gambar 1 tersebut, dapat dilihat pada Tabel 1.

Tabel 1 Tahapan Penelitian

\begin{tabular}{|c|c|}
\hline Tahap & Keterangan \\
\hline Planning & $\begin{array}{l}\text { Pada tahap ini peneliti mengumpulkan informasi dari berbagai } \\
\text { sumber di internet. Juga membaca dokumentasi yang ada } \\
\text { pada } R F C \text {. Serta melihat implementasi dari website lain yang } \\
\text { menggunakan } O A u t h 2.0 \text {. Mengumpulkan informasi dan } \\
\text { proses-proses yang perlu diimplementasi agar fitur otentikasi } \\
\text { OAuth } 2.0 \text { dan } P K C E \text { berjalan dengan sesuai dan memenuhi } \\
\text { kebutuhan untuk produk multitenant }\end{array}$ \\
\hline Design & $\begin{array}{l}\text { Pada tahap ini peneliti mencoba merancang kebutuhan sistem } \\
\text { yang dibutuhkan. Rancangan sistem dilakukan peneliti berupa } \\
\text { rancangan sistem database, rancangan sistem tampilan } \\
\text { proyek, dan rancangan alur program yang akan dibaut. } \\
\text { Rancangan ini akan digunakan untuk proses penelitian ini } \\
\text { pada fitur otentikasi OAuth } 2.0 \text { dan } P K C E\end{array}$ \\
\hline Coding & $\begin{array}{l}\text { Pada tahapan ini peneliti mencoba mengimplementasikan } \\
\text { rancangan yang dibuat pada tahap sebelumnya. Dimana } \\
\text { meliputi proses otentikasi pada client, proses autorisasi untuk } \\
\text { akun yang mencoba login, dan penukaran code yang didapat } \\
\text { dengan token. }\end{array}$ \\
\hline Test & $\begin{array}{l}\text { Tahap ini peneliti melakukan beberapa pengunjian aplikasi } \\
\text { dengan memberikan memberapa data dan skenario. Seperti } \\
\text { menggunakan client yang sudah terdaftar pada sistem dan } \\
\text { client yang tidak terdaftar atau client sudah dihapus datanya } \\
\text { dari server. }\end{array}$ \\
\hline Software Increment & $\begin{array}{l}\text { Pada tahap ini adalah penelitian untuk mendemonstrasikan } \\
\text { aplikasi yang sudah dibuat ke perusahaan yang akan memakai } \\
\text { fitur ini. }\end{array}$ \\
\hline
\end{tabular}

\section{HASIL DAN PEMBAHASAN}

\subsection{Hasil Penelitian}

Implementasi dan perancangan sistem login merupakan hasil dari perancangan yang telah dilakukan sebelumnya. Berikut adalah hasil dari implementasi sistem yang telah dibuat.

Pada Gambar 2 merupakan halaman client yang mengintegrasikan webnya dengan sistem login yang dirancang sebelumnya. Terdapat satu tombol yang digunakan untuk melakukan aksi untuk melakukan proses otentikasi dari client ke server. Jika client tersebut terdaftar maka otomatis akan diarahkan kehalaman login SSO.

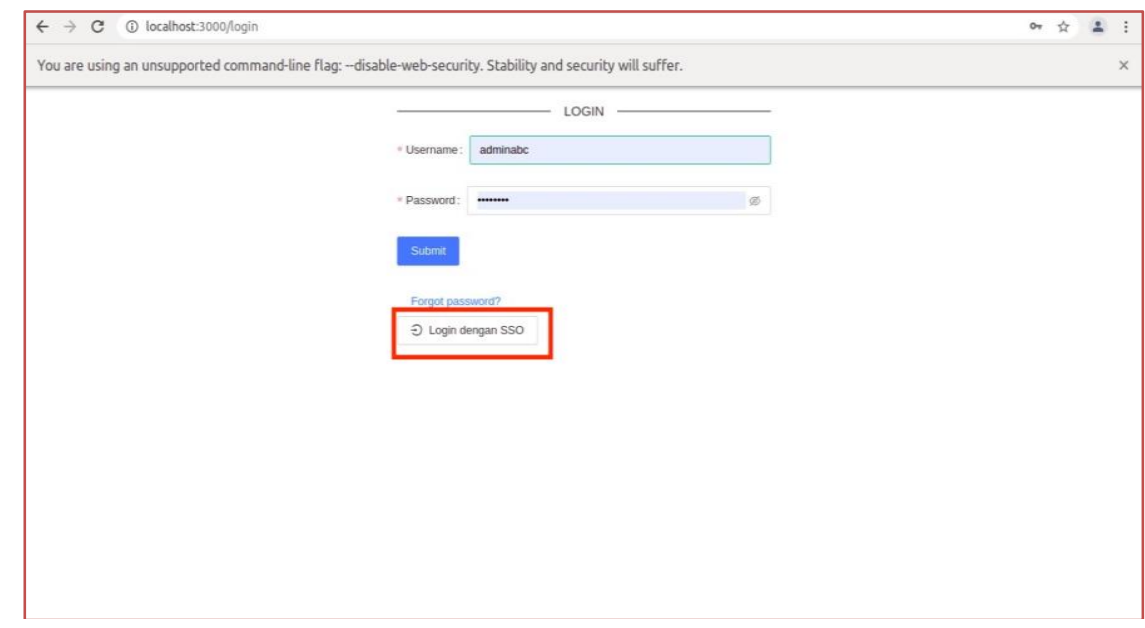

Gambar 2. Tempilan client dan tombol SSO 
Tampilan halaman login SSO merupakan halaman terpusat yang akan digunakan oleh setiap client untuk melakukan pengecekan terhadap akun yang digunakan oleh user nantinya. Tampilan halaman login SSO bisa dilihat pada Gambar 3.

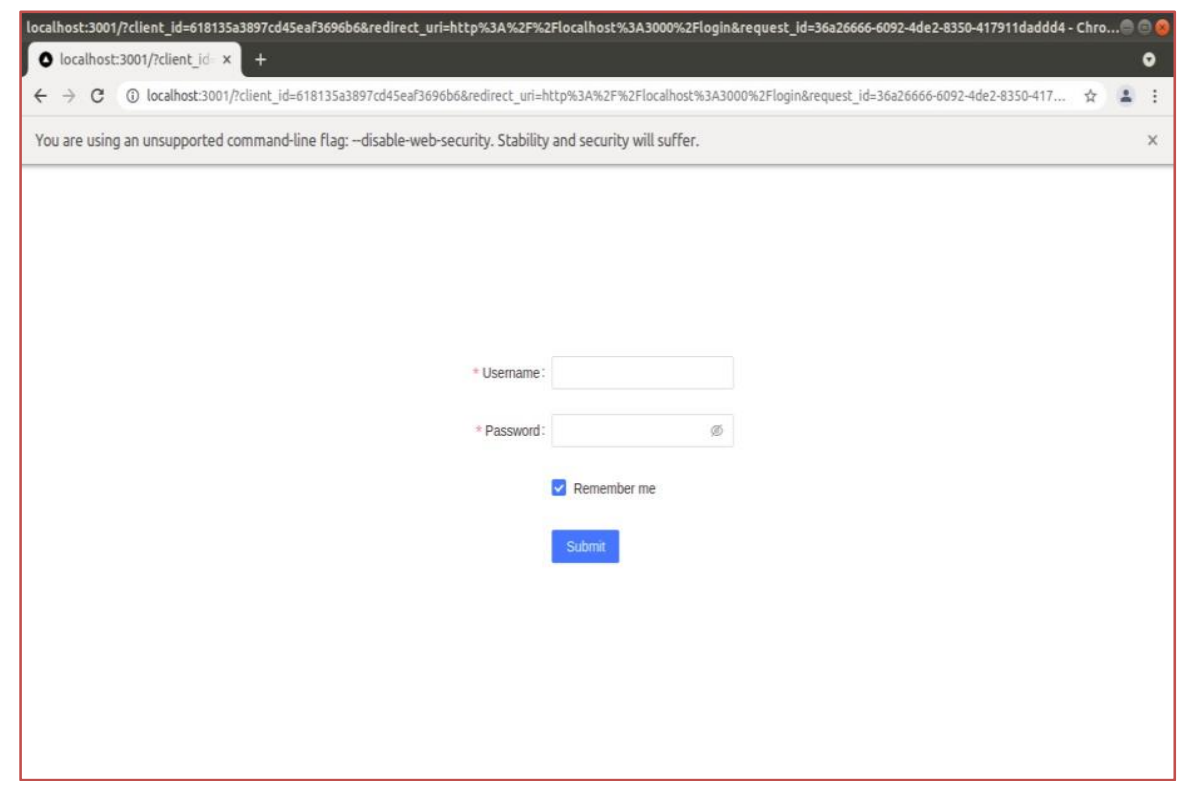

Gambar 3. Tampilan form login SSO

Pada Gambar 4 ini merupakan contoh halaman dimana user sudah berhasil melakukan login.

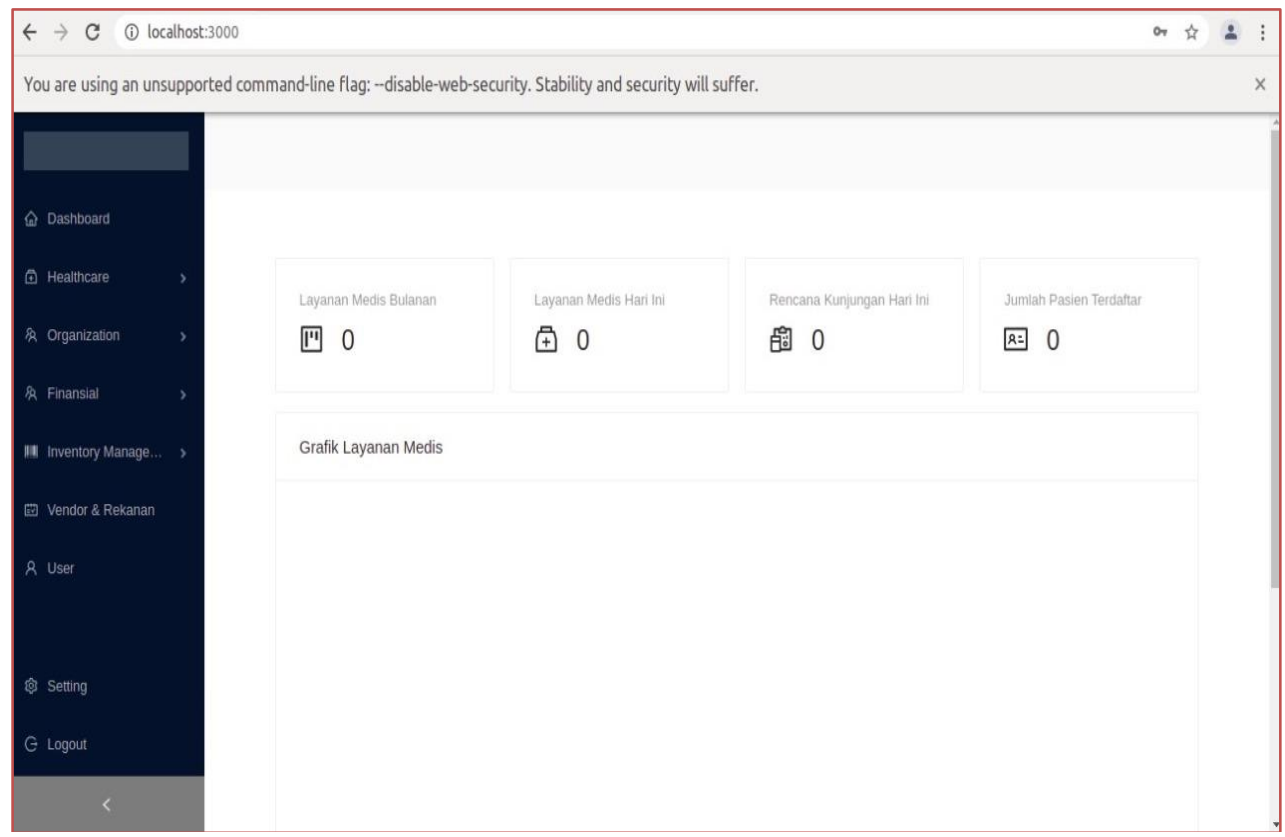

Gambar 4. Halaman client berhasil login

\subsection{Contoh Sub-Bab Kedua}

\section{a. Implementasi Sistem di Client Implementasi Sistem}

Implementasi untuk menggunakan SSO ini pada sisi client hanya perlu menambahkan beberapa baris kode program untuk prosess otentikasi client dan pertukaran code yang nantinya akan diganti dengan access token.

Bisa dilihat Gambar 5 client perlu membuat code_challenge_method, code_verifier, dan state yang nantinya ini digunakan untuk tahap pertukaran token. 


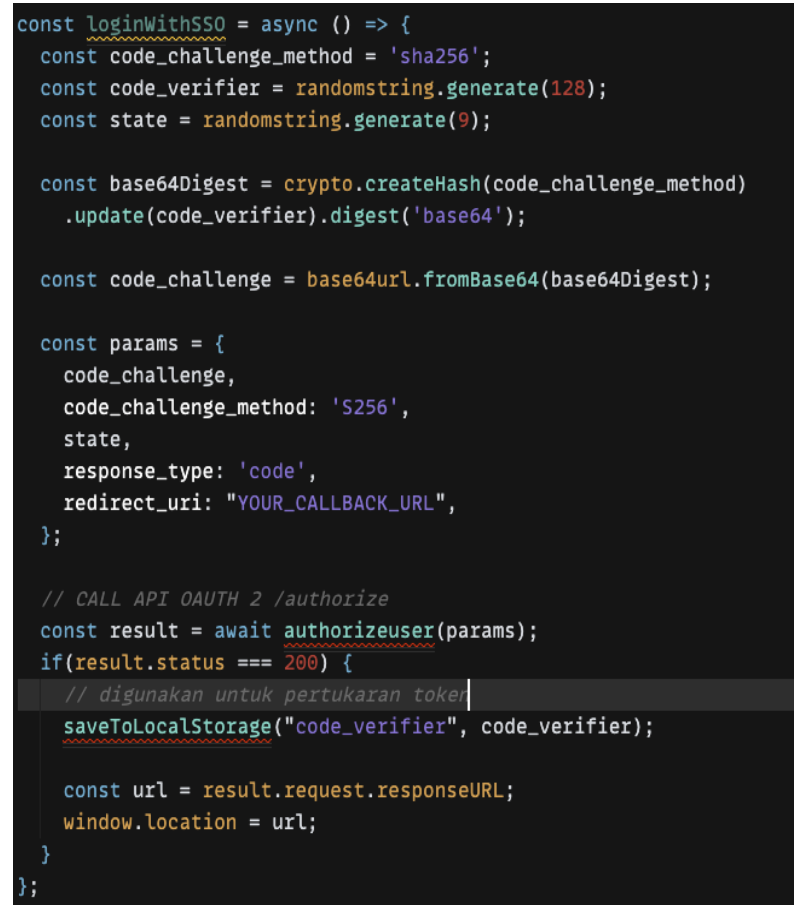

Gambar 5. Otentikasi client

Bisa dilihat pada Gambar 6 adalah merupakan contoh pertukaran code yang untuk yang sudah berhasil login ditukar dengan access token. Dimana access token ini akan digunakan untuk tiap request.

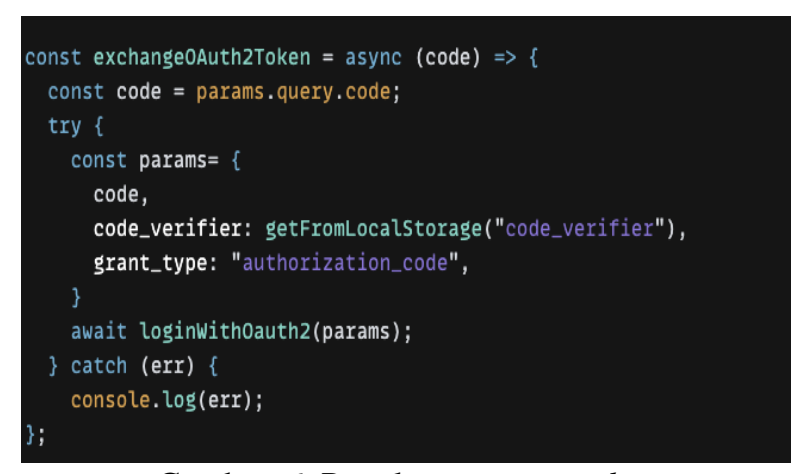

Gambar 6. Pertukaran access token

Jadi client yang menggunakan SSO ini tidak perlu membuat banyak code untuk login seperti form untuk username dan password, serta halaman khusus untuk login. Hanya perlu menambahkan beberapa baris kode program

\section{b. Pengujian Sistem}

Disini peneliti menggunakan 5 credential client yang akan digunakan untuk proses pengujian sistem. Hasil penelitian dapat dilihat pada Tabel 2.

Tabel 2. Hasil Pengujian Client

\begin{tabular}{cclcl}
\hline No & \multicolumn{1}{c}{ Data } & Input & $\begin{array}{c}\text { Output yang } \\
\text { diharapkan }\end{array}$ & Hasil pengujian \\
\hline 1 & \multirow{2}{*}{} & POST /identity/v1/oauth2/authorize & $\begin{array}{c}\text { Response code } \\
\text { HTTP/1.1 }\end{array}$ & $\begin{array}{l}\text { HTTP/1.1 302 Found } \\
\text { Location: }\end{array}$ \\
& & & http://localhost:3001?client_id=61a76b6b \\
& Host: localhost:8081 & & f04e26652cb172f3\&redirect_uri=http\%3 \\
& "_id" : & Connection: keep-alive & A\%2F\%2Flocalhost\%3A3000\%2Flogin\& \\
& ObjectId("61a76 & Content-Length: 220 & Pragma: no-cache & request_id=02da84b5-2b59-4f6c-8012- \\
& b6bf04e26652cb & Cache-Control: no-cache & 1b004e7692a9 \\
& 172f3"), & "Chromium";v="96", "Google & Date: Sun, 12 Dec 2021 07:20:50 GMT
\end{tabular}




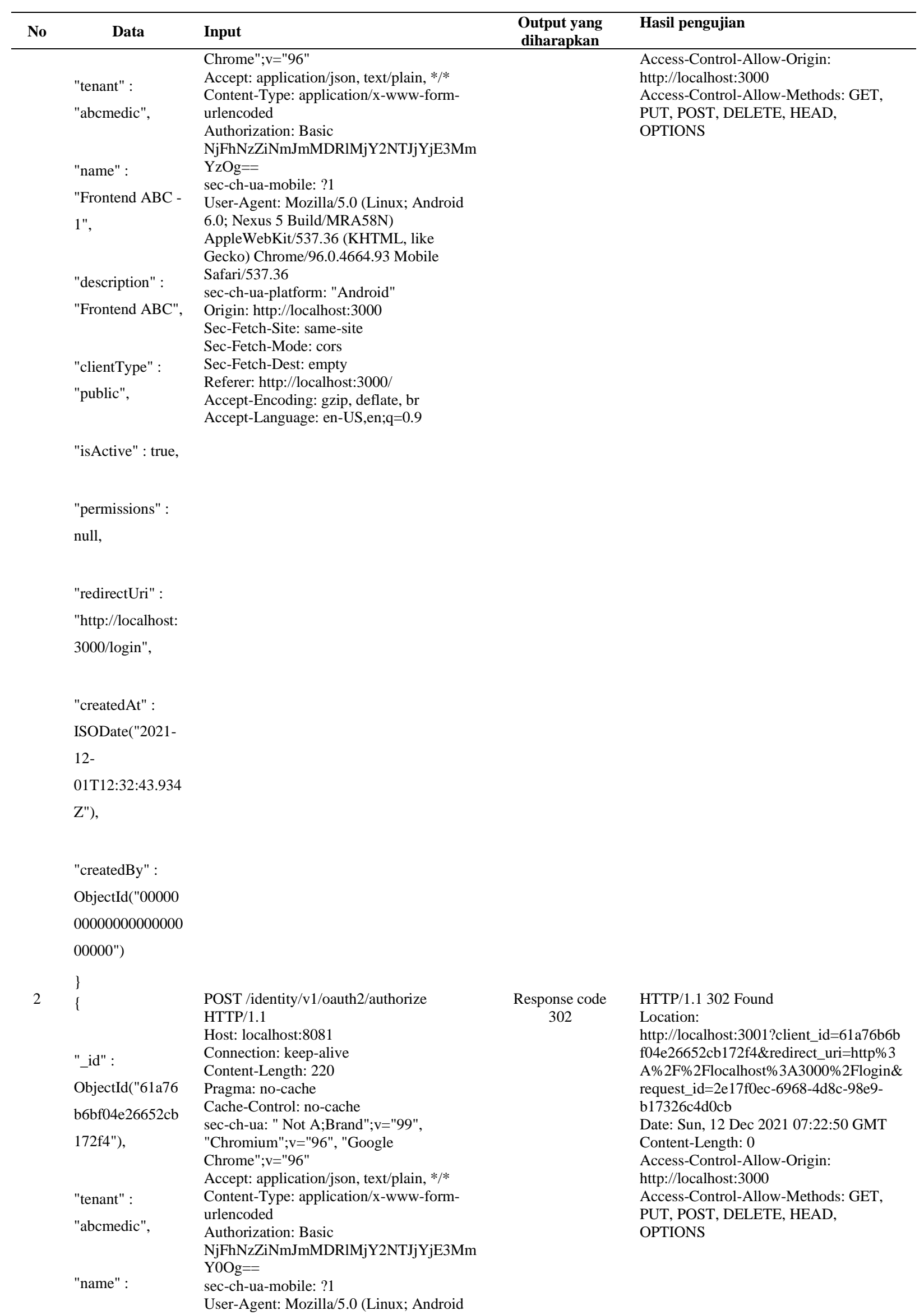




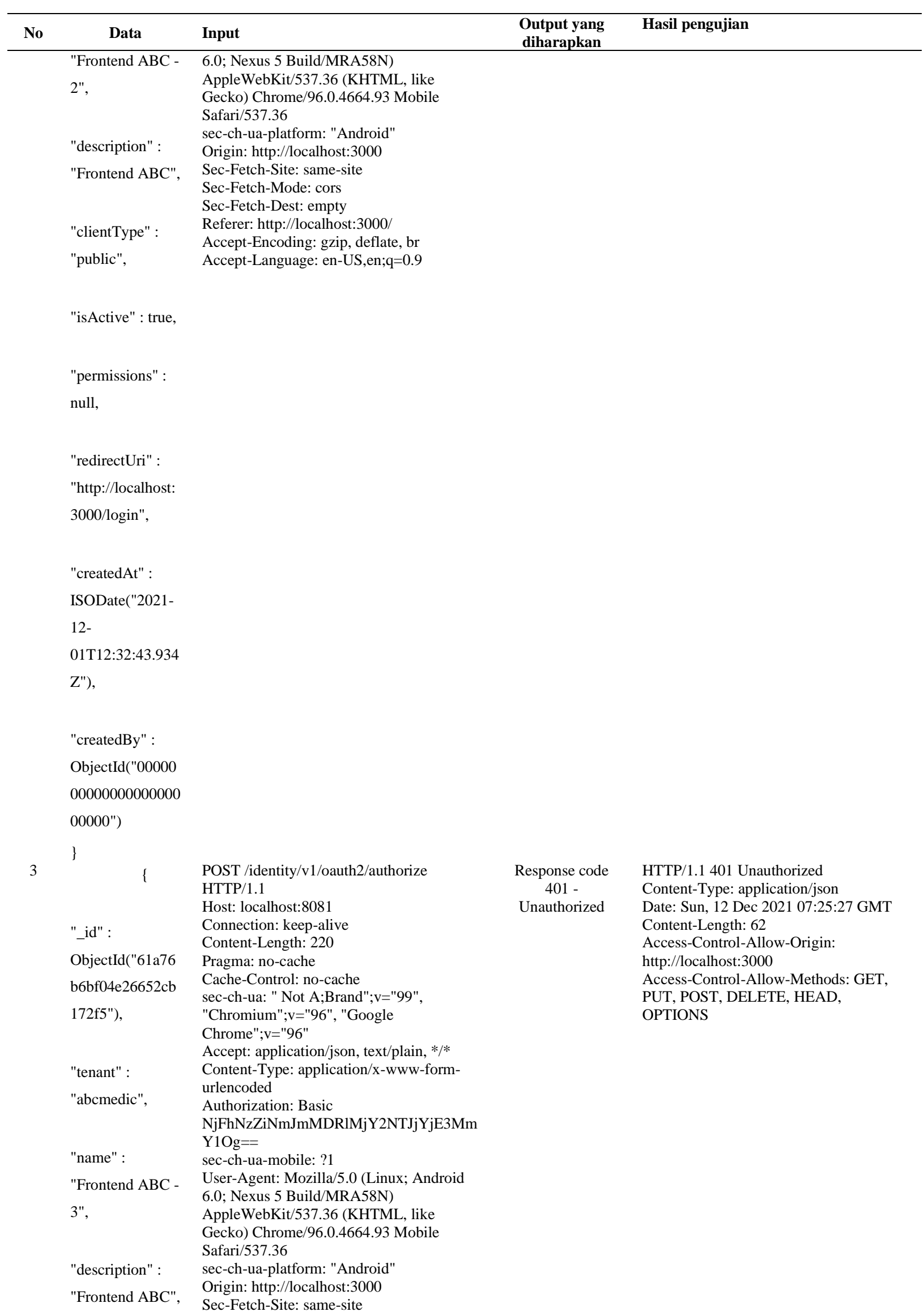




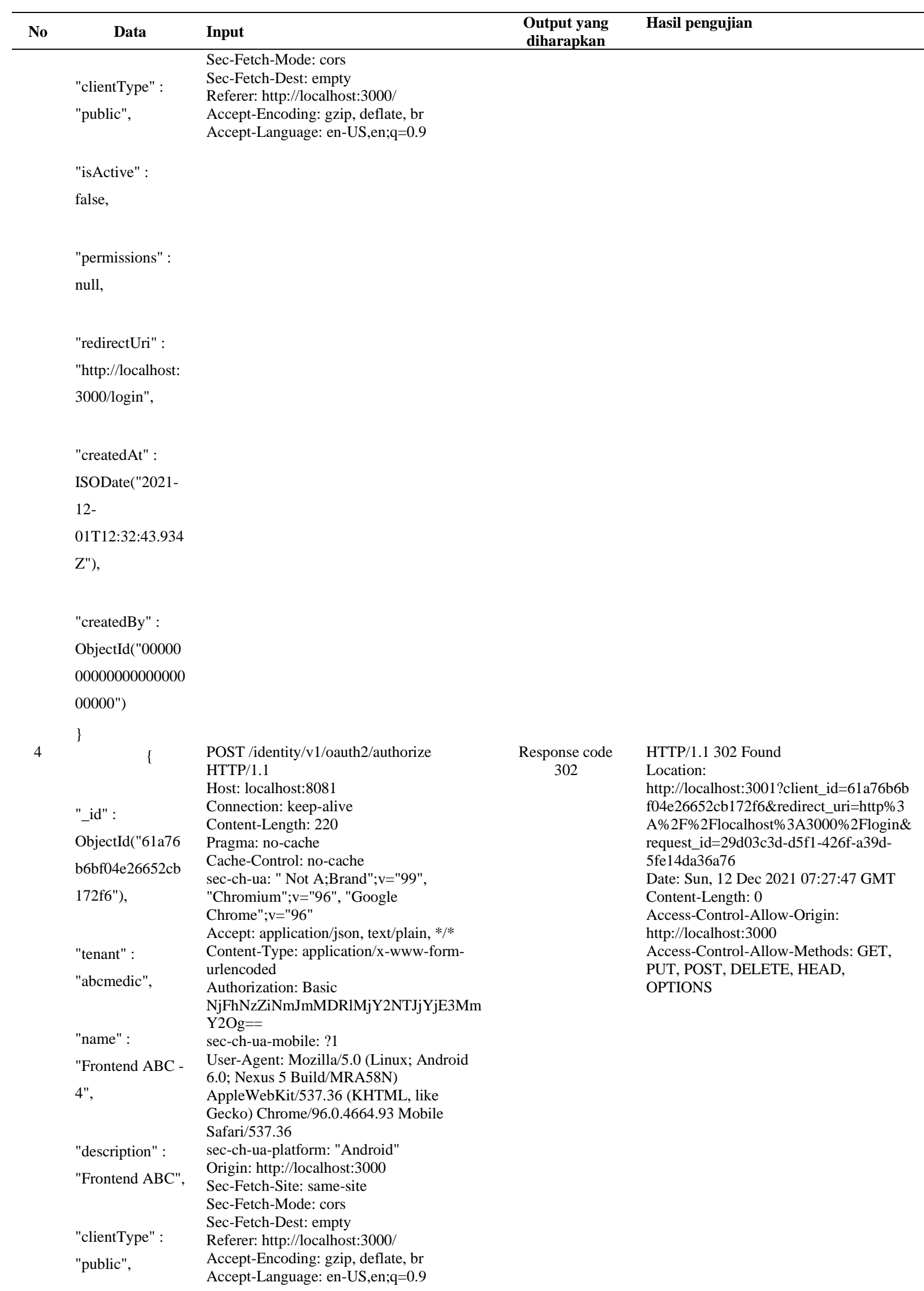




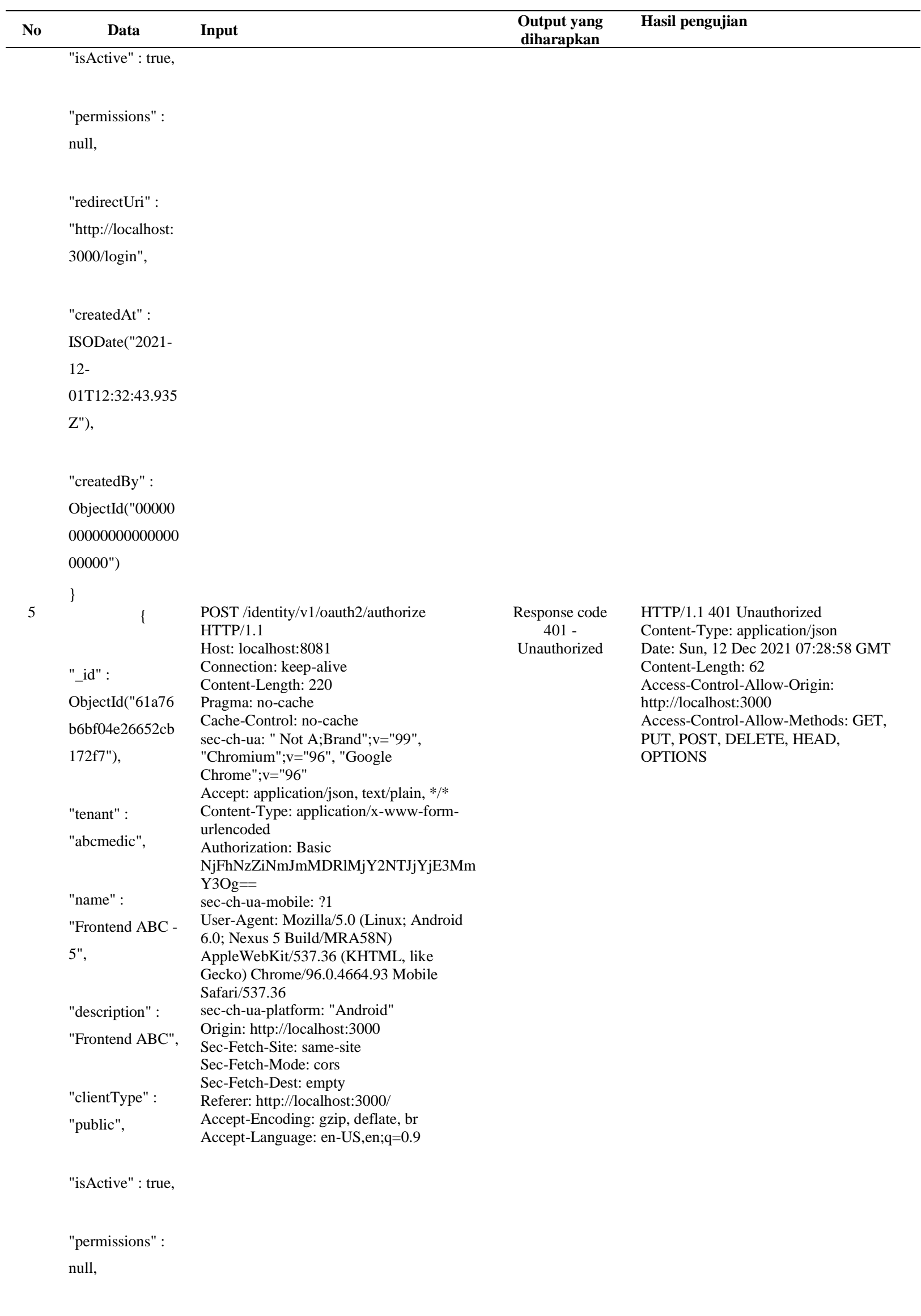




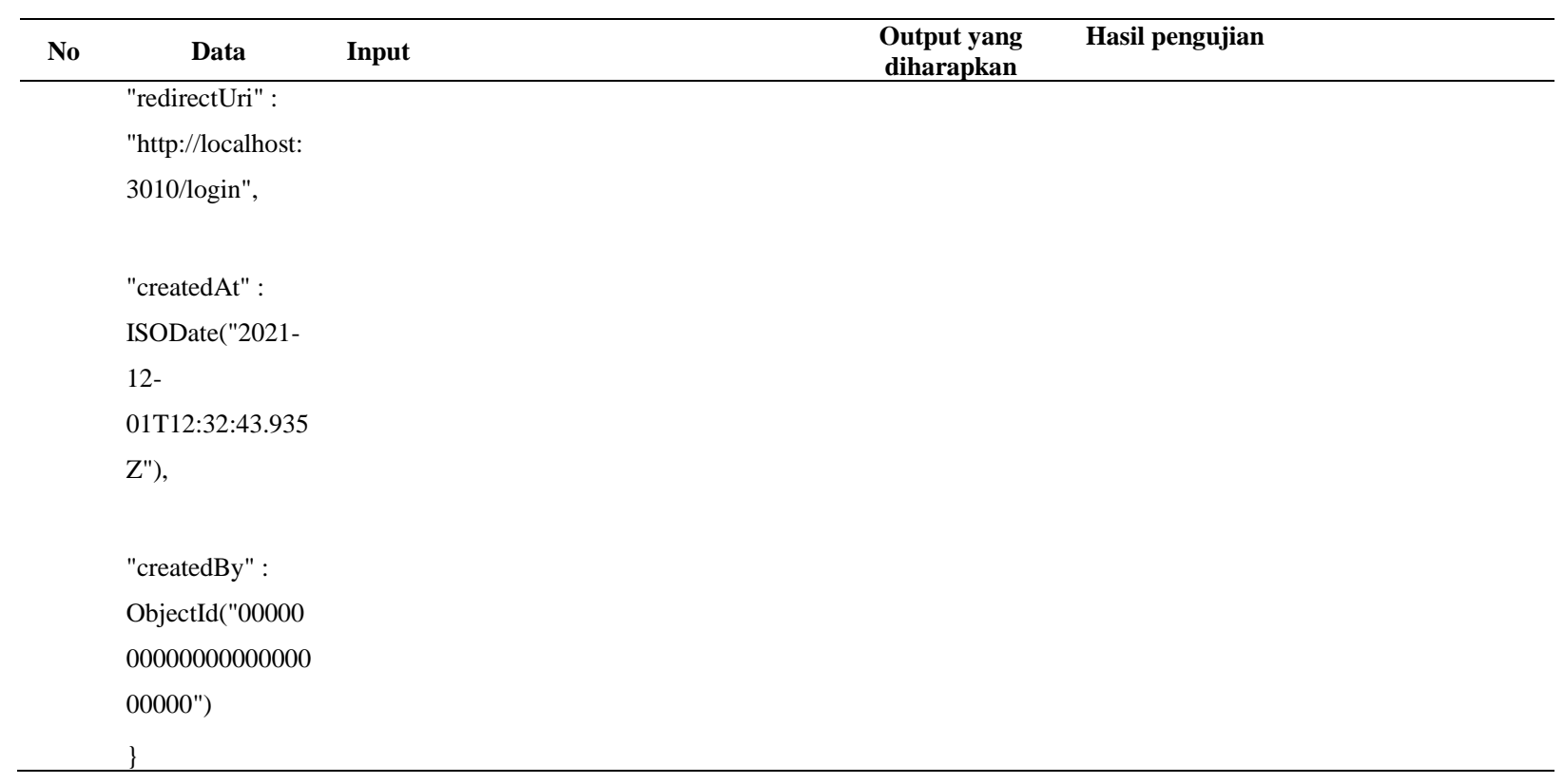

Kita bisa lihat pada Tabel 2 terdapat dua pengujian yang gagal yaitu pada nomor 3 dan 5 . Dan yang lainnya berhasil.

Pada pengujian nomor 3 itu terdapat field isActive dimana nilai dari field itu adalah false. Jika client memiliki nilai isActive adalah false, maka client tersebut bisa dibilang sudah tidak bisa melakukan atau menggunakan sistem SSO ini. Bisa dilihat pada Gambar 7 client akan mendapatkan error 401 unauthorized pada saat melakukan permintaan ke server. Jadi server tidak akan meneruskan atau menolak proses yang seharusnya dilakukan.

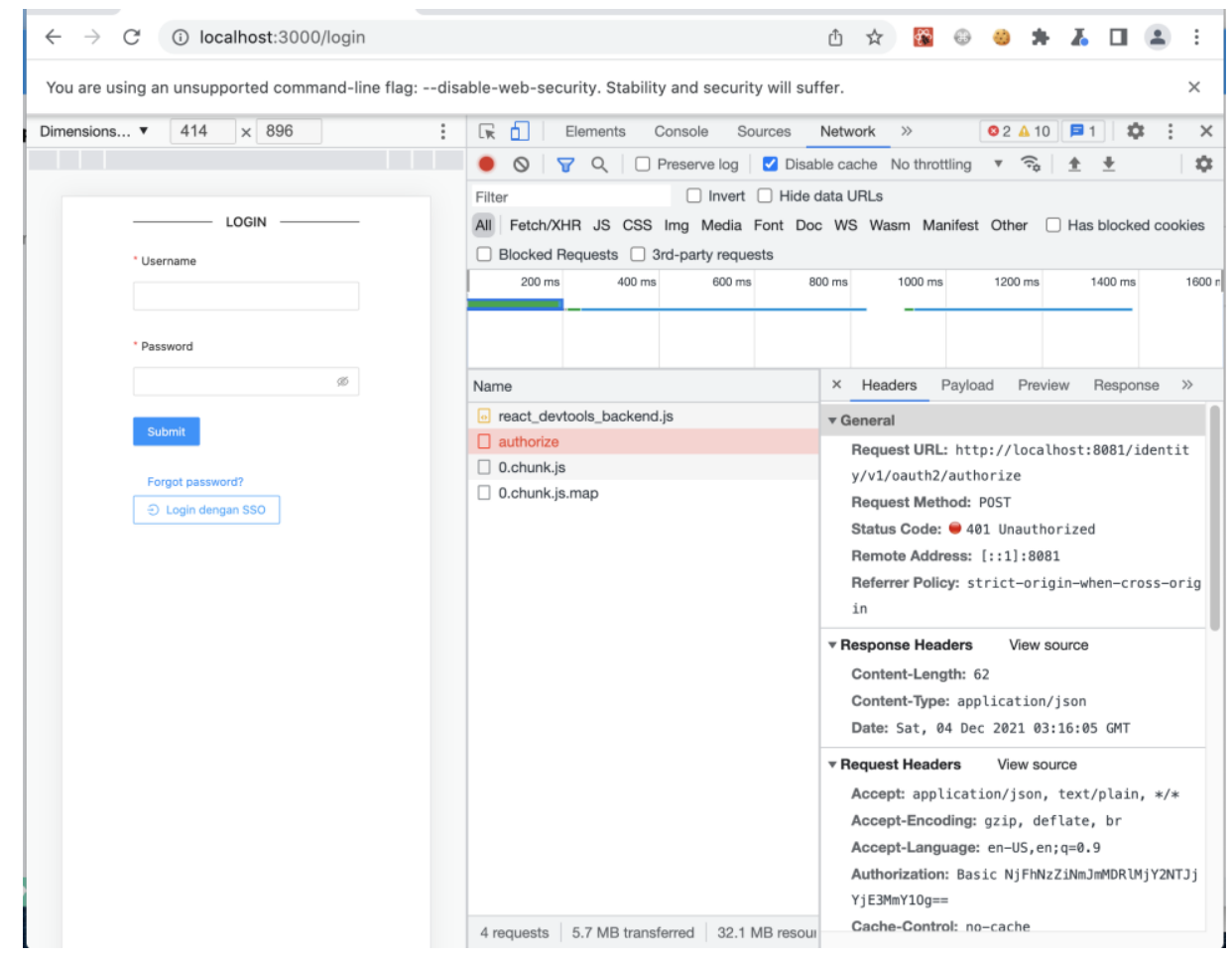

Gambar 7. Error 401 untuk unregistered client

Pada pengujian nomor 5 itu gagal mendapatkan token. Pada pengujian nomor 5 ini penguji mencoba melakukan request dari domain yang berbeda dengan nilai dari redirectUri yang disimpan 
dalam database server. Bisa dilihat pada Gambar 8. Pada gambar tersebut permintaan ke server untuk otorisasi mendapatkan response unauthorized dengan error code 401. Itu membuktikan permintaan tersebut ditolak oleh server.

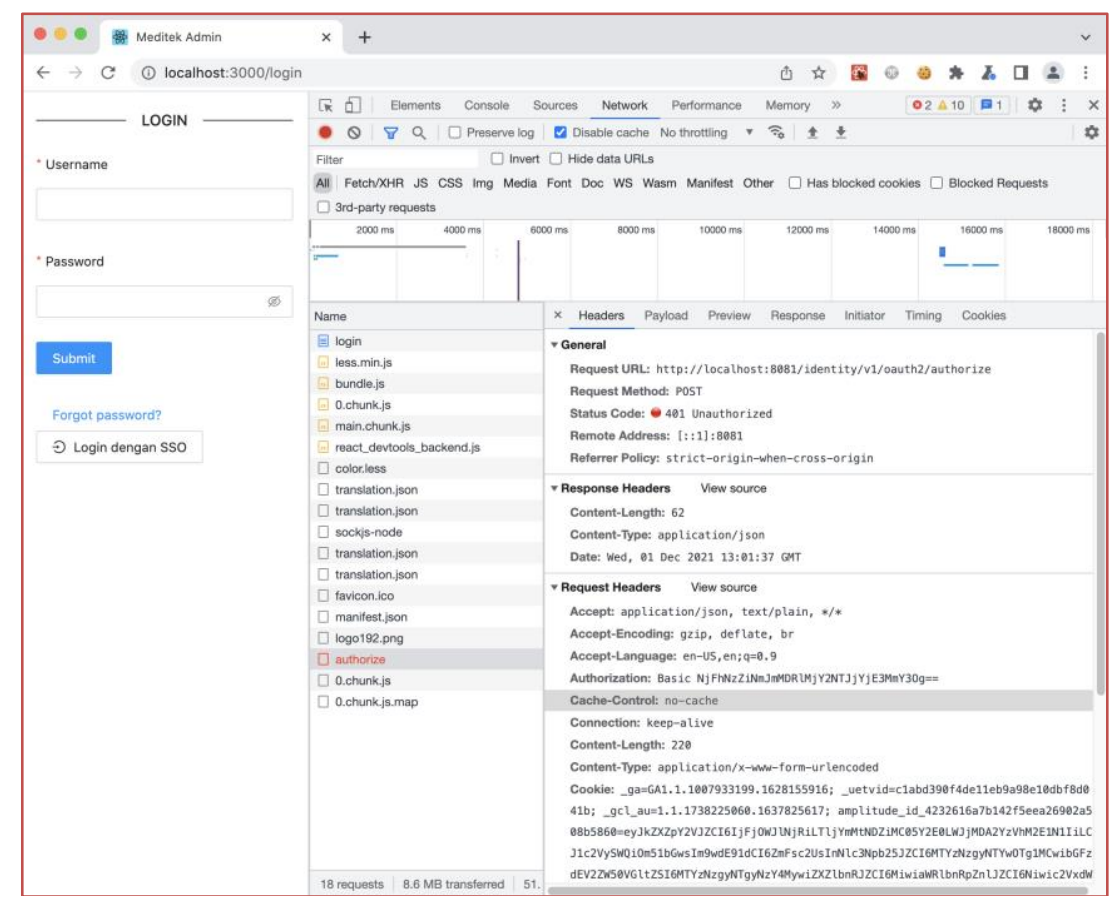

Gambar 8. Error dengan domain berbeda

\section{KESIMPULAN}

Dengan menggunakan otentikasi OAuth 2.0 kita bisa dengan mudah menghapus hak akses untuk sebuah client tanpa harus mengubah source code di sisi client. Penerapan OAuth 2.0 lebih aman jika dibandingkan menggunakan otorisasi API standar seperti basic-auth API ataupun API Key. Karena ada proses otentikasi client yang perlu dilakukan sebelum melakukan proses otentikasi user. Client tidak perlu membuat sistem login sendiri untuk memverifikasi akun pengguna.

\section{DAFTAR PUSTAKA}

[1] N. Sulisrudatin, “Analisa Kasus Cybercrime Bidang Perbankan Berupa Modus Pencurian Data Kartu Kredit," Jurnal Ilmiah Hukum Dirgantara-Fakultas Hukum Universitas Dirgantara Marsekal Suryadarma, vol. 9, 2018.

[2] Aminudin, "Implementasi Single Sign On Untuk Mendukung Interaktivitas Aplikasi E-Commerce Menggunakan Protocol Oauth," Seminar Nasional Teknologi dan Rekayasa (SENTRA) SSN (Cetak) 2527-6042eISSN (Online) 2527-6050, pp. 9-13, 2016.

[3] M. Elsera, "Implementasi Single Sign On Pada Web Menggunakan Protocol Oauth Facebook," Buletin Utama Teknik, vol. 16, no. 3, pp. 179-185, 2021.

[4] E. D. Hardt, "The OAuth 2.0 Authorization Framework," October 2012. https://datatracker.ietf.org/doc/html/rfc6749. (accessed december 2021)

[5] I. K. D. Senapartha, "Implementasi Single Sign-OnMenggunakan Google Identity, REST dan OAuth 2.0 Berbasis Scrum,” Jurnal Teknik Informatika dan Sistem Informasi, vol. 7, no. 2, pp. 307-320, 2021.

[6] T. Krusen, "PKCE: What and Why?," Dropbox, 4 December 2020. https://dropbox.tech/developers/pkce--what-and-why-. (accessed october 2021)

[7] R. S. Pressman, Software Engineering: A Practitioner's Approach, Seventh Edition, New York, The McGraw-Hill Companies, Inc, 2010 